\title{
Factors Motivating Broadband Adoption in Thailand
}

\author{
N. Tiamnara, N. Madan, and S. Malisuwan
}

\begin{abstract}
The term broadband varies from country to country and yesterday's broadband could be today's narrowband. National Broadcasting and Telecommunications Commission of Thailand puts significant emphasis on increasing broadband penetration as the adoption of broadband leads to high productivity gain which further leads to an increase in GDP. The purpose of this research is to study the motivation behind broadband adoption in Thailand in order to utilize that information to increase the low broadband penetration in Thailand. Survey was distributed to university students in Mae FahLuang University in Chiangrai and quantitative analysis was conducted. The findings of this research confirm that broadband adoption amongst Thai people is due to Hedonic Outcomes (HO), Social Influence (SI), Self Efficacy (SE)and Facilitating Conditions Resources (FCR). However, Utilitarian Outcome or utilizing broadband to enhance household activities has no significant influence on broadband adoption in Thailand. The clarity gained from this research on the motivation behind broadband adoption in Thailand can be used to help the ICT and NBTC in utilizing the correct method to increase broadband penetration in Thailand.
\end{abstract}

Index Terms-Broadband adoption, hedonic outcome (HO), facilitating conditions resources (FCR), utilitarian outcome (UO), self efficacy (SE) and social influence (SI).

\section{INTRODUCTION}

The diffusion of broadband, a technology that enables high speed transfer of data is unequivocally related to increase in internet access [1]. Institute of Electrical and Electronic Engineers (IEEE) define broadband as a technology that has 'wideband' which is bandwidth of more than $1 \mathrm{MHz}$ and has transmission rate to send and receive data at a speed higher than 1.5 Mbps. Broadband is referred to as wireless high speed access technology. However, because the technology of broadband continuously changes, there is no clear cut definition of broadband. High-speed internet access like broadband has strengthened global communications in comparison to dial up internet. Broadband as a technology has better capability to support data traffic, video streaming, and television and radio signals. It does not provide benefits only in terms of speed but has capacity for enormous bandwidth which can transmit wider coverage signals hence, increasing better internet access coverage. Apart from providing tremendous increase in speed and coverage for internet access in comparison to traditional dial up, Broadband also increases economic benefit and GDP by allowing new services and new businesses in the form of

Manuscript received January 21, 2014; revised April 25, 2014. Financial support for this research paper is provided by National Broadcasting and Telecommunications Commission, Bangkok, Thailand.

The authors are with the National Broadcasting and Telecommunications Commission, Bangkok, Thailand (e-mail: noppadol.t@nbtc.go.th, navneet.nbtc@gmail.com, settapong.m@nbtc.go.th) e-commerce. Therefore on a national level, broadband is viewed as a backbone of a country and is apparent to facilitate the nations' competitiveness on an international level [2]. Broadband infrastructure is an indispensable component in a knowledge economy [3]. Due to a myriad of benefits brought about by broadband, adoption has been growing throughout the world.

It is proven fact that an increase in capital expenditure to create ubiquitous adoption of current broadband technologies will result in an increase in GDP [1], [3]. While current deployment of broadband is more advanced in some countries than others, Thailand is still lagging behind neighboring countries in broadband adoption [find source]. The main barrier related to low internet penetration in Thailand is low income level of larger number of the population and developing fixed broadband infrastructure especially in the rural areas [find source]. Policy makers, media companies, marketing firms and economists are closely keeping an eye of deployment of broadband because the way the general public access the types and the amount of data they access will change the game for all these stakeholders. Broadband is seen as a means to substitute traditional entertainment media. To analyze factors that motivate the adoption of broadband provides a deeper understanding as to what type of information consumption is of interest to users. This is imperative as broadband adopted for the consumption of online content is a substitute of traditional media such as television and print publishing; therefore the impact on these stakeholders is pertinent for policymakers in developing broadband policy [4]. Further, broadband may increase user's information consumption in regards to product details, product reviews, product price comparisons, online sales and specialty retailers, which will be of interest to marketing firms, businesses, economists and governments in regards to protection and security on online consumer rights. Beyond economic growth and job creation, broadband also has a positive effect on consumer surplus in terms of the benefits to end user that is not captured in GDP statistics, which include speedy access to information, health and entertainment information and innovative services brought about by broadband.

There are several researches that have been conducted to understand broadband deployment and adoption in developed countries such as UK [5] and in leading developing country such as South Korea [6]. However, very few studies have investigated broadband adoption within the context of developing countries that have late broadband roll out, delay in broadband infrastructure development, and an adoption rate that is lagging behind that of its neighboring countries [7]

Moreover, researchers in IS field have exhausted the study in adoption of broadband at organization and individual level but studies in regards to household adoption of broadband [8] 
as a consequence of ICT broadband plan has not been conducted in Thailand.

While there is a lack of research in a country that fits these criteria, a research on factors that motivate broadband adoption in Thailand should provide deep insight considering Thailand fits the criteria aforementioned. This research aims to provide a clear understanding on what factors motivate broadband adoption, for policymakers, marketing firms, businesses and economists in Thailand. Moreover, National Broadcasting and Telecommunications Commission, aims to use the results of this study to enhance national broadband policy particularly while broadband penetration increases.

Therefore, as a guideline for this research in broadband adoption in Thailand, this research aims to answer the following questions:

What are the factors that influence decision for Broadband adoption in Mae FahLuang University students' households?

Which factors have the greatest impact towards broadband adoption in Mae FahLuang University Students' households?

\section{LITERATURE REVIEW}

In the 90s, information system academic papers have focused entirely on adoption and diffusion of information technologies at the individual level and organization level but none on household adoption models. Further information system models used to study acceptance, adoption and usage behavior of users include the "Theory of Reasoned Action (eg.[9], [10]), the Technology Acceptance Model (e.g. [10]), the Theory of Planned Behavior (e.g.,[11], [12]), the Model of PC Utilization [13], the Decomposed Theory of Planned Behavior [14], and Innovation Diffusion Theory (e.g., [15]-[17]). These technology adoption studies explained focus on individual adoption in organizations ([18], [19]) while in modern day due to changing circumstances and technology being a necessity rather than a luxury, focus has moved from individual adoption of technology to household adoption of technology.

However, in the modern day ICT policies require National Broadband plan which are more focused on increasing adoption of broadband in households ([8],[20];. While there have been several researches on household broadband adoption in South Korea, Malaysia and United Kingdom, the outcomes on the motivation towards adoption of broadband differ distinctively between these countries and are influenced by variety of factors including but not limited to culture, developed or developing nature of the country and distribution of age groups etc.

\section{A. Thailand Broadband Adoption}

Fig. 1. illustrates a broadband adoption comparison of other countries with Thailand. Although Broadband is no longer considered as a new technological invention, the adoption rate in Thailand is about 50\% which is below expectation level as compared to many countries including Korea, Japan and United Kingdom. Household possession of internet-enabled computers in Bangkok reached $40.8 \%$ in 2008 but stood at only $5.4 \%$ in Northern regions and $5.5 \%$ in the North East. However, household broadband penetration in Thailand remains low due to high costs of Internet services and computers as well as lack of quality infrastructures outside Bangkok areas. Several studies have offered insights on penetration of broadband in developing countries and Thailand is considered slow in adoption of Broadband. "This may be due to the delayed rollout of broadband services, slower infrastructure growth, lower tele-density and slower pace of adoption that contribute to the lack of broadband adoption research" [21]. While Thailand is lacking behind other developing countries such as South Korea, Japan and developed country United Kingdom on broadband adoption, it is vital to conduct broadband adoption study to assist in explaining factors that may hasten the process of broadband adoption. Further it is suggests that broadband technology can help advance an economy and increase GDP by a large extent, therefore this study is more critical now than ever.

"Given such perceived benefits, it is essential to comprehend the factors presently affecting the consumption, acceptance and usage of broadband among Thai consumers and subsequently, how to further encourage the adoption and usage of broadband?"

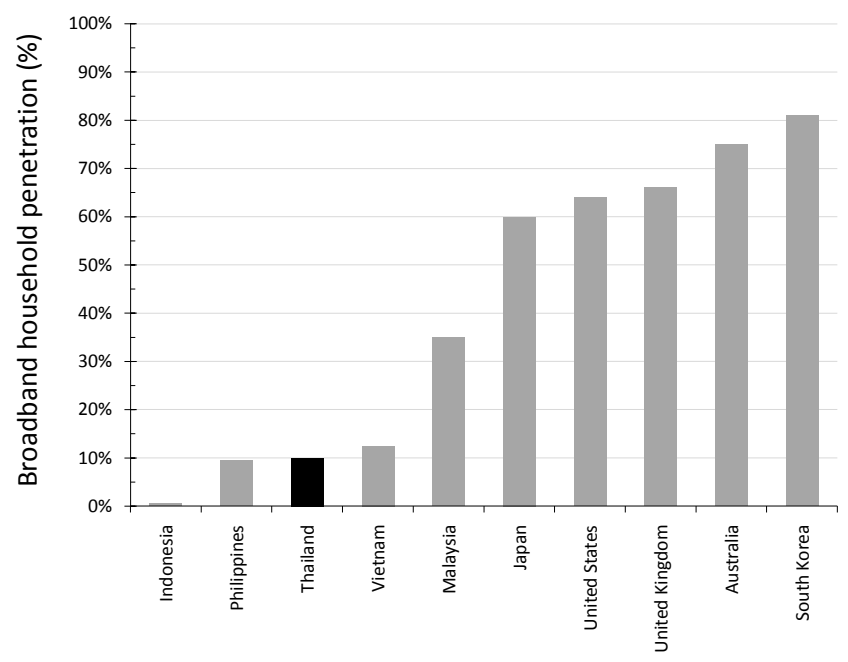

Fig. 1. Comparison of broadband adoption.

\section{B. Broadband Adoption Factors}

\section{Price and speed for broadband}

Industry factors such as price and speed might influence broadband penetration and is a key factor in promoting broadband demand therefore contributing to higher broadband adoption. Lower prices can increase number of subscribers for broadband adoption and in a competitive market, broadband prices will be fairly and optimally priced therefore, resulting in lower prices. Garcia-Murillo (2005) proved through statistical analysis that fixed broadband price and competition has been influential broadband adoption [22].

In the UK, a research indicated that broadband service providers used factors such as speed, download limit, duration of contract and monthly cost as means of attracting customers [3].

However, although price is expected to increase broadband adoption in the short-term, it is argued that a sustainable business model for the long-term requires a detailed understanding of other factors other than speed, 
download limit, duration of contract and monthly cost. Therefore, the aim of this paper is to understand the influence of factors such as utilitarian outcomes (UO), hedonic outcomes (HO) and perceived resources as proposed in previous research [5], [22].

Well-established theories such as TRA, TPB, DTPB, Diffusion of Innovation Theory, and Technology Acceptance Model (TAM) has been widely adopted in past research to explain diffusion and user acceptance of technology. "The limitation of the decomposed TPB detailed constructs for this research was that they did not examine the adoption of a technology in the context of the household. This is because the decomposed TPB was developed to examine 'users' adoption of IT within organizational settings"[22]. Therefore, to explain household adoption of broadband, this research will adopt "The Conceptual Model of Broadband Adoption (MBA)". This model is a well established model for explaining household adoption of broadband and is developed from Decomposed Theory of Planned Behavior (DTPB) and Theory of Planned Behavior.

The proposed conceptual model MBA assumed that the dependent variable "broadband adoption" is influenced by several independent variables which are attitudinal (UO and $\mathrm{HO}$ ), normative (social influences - SI), control factors (self efficacy - SE and facilitating resources and demography (age).

\section{The Conceptual Model of Broadband Adoption (MBA)}

\section{1) Behavioral intention}

Behavioral intention is "consumers' intention to subscribe or intention to continue current subscription". In this case, it is the decision to make use of broadband internet in the future[22].

\section{2) Utilitarian outcome}

"This factor is associated with the utility of benefits that can be obtained from broadband and to know for what purpose the consumer of the innovation can exploit it in the household environment" [2]. In other words, it is the extent to which broadband internet usage enhances the effectiveness of household activities such as undertaking office work at home, children's homework, finding information about product or service, purchase and home business [8].

\section{3) Hedonic outcomes}

It is pleasure derived from using broadband such as entertainment potential that broadband can provide including but not limited to online radio, streaming audio, real time streaming of movies or videos, online games and online casino [21].

\section{4) Social influence}

It was considered that social influence of family, friends and social network in the modern day can influence broadband adoption [8]. While social influences influence PC purchase, it is expected to influence household broadband adoption as well [8]. In several studies, social influences are also called primary influence [23].

\section{5) Self efficacy}

"Self-efficacy is defined as the perceived ability or skill to operate computers and the Internet (narrowband or broadband) without the assistance of others"[20]. For instance, the user in the household feels comfortable in using the internet, it is easy for them to operate and they understand how to use the internet. Therefore, in this construct we can include perceived ease of use, perceived knowledge, and perceived skill of use of broadband.

\section{6) Facilitating resources conditions}

"Facilitating conditions resources is defined as the perceived level of resources when subscribing to broadband"[2]. Therefore, "it represents the perceived control over the personal or external factors that may facilitate or constrain the broadband adoption" [24]. For instance, the annual household income is enough to afford broadband, it is not too costly for this household to purchase new computer that is compatible to broadband, it is not too costly to subscribe to broadband at its currently subscription fee and the state of the household is such that they can subscribe to broadband if they wanted to.

\section{7) Country comparison on broadband adoption}

Past researches were conducted to highlight factors that influence broadband adoption in many countries [23]. In a developed country such as United Kingdom, it was found that Utilitarian Outcome, Hedonic Outcome, Social Influence (Primary Influence), Self Efficacy, and Facilitating Resources Conditions influences Behavioral Intention (BI) to adopt broadband. Nevertheless, the factors that impede broadband adoption in United Kingdom are high price (facilitating resources conditions), lack of content and lack of awareness of the general public regarding broadband [23]. In developing countries such as Bangladesh, Pakistan and Malaysia that experience slow broadband adoption due to because they are currently experiencing slow IT infrastructure development and low broadband adoption rate just in the case of Thailand. In Bangladesh, attitude influences (Hedonic Outcome and Utilitarian Outcome), social influence (SI or primary influence) and facilitating resources conditions influence Behavior Intention to adopt broadband in Bangladesh [21]. Whereas in Pakistan, social influence (SO or primary influence), facilitating resources conditions and perceived ease of use is what influences behavioral intention to adopt broadband [7]. While in Malaysia, Hedonic Outcome, Self Efficacy, Facilitating Resources Conditions and Social Influence (Primary Influence) have significant influence on behavioral intention to adopt broadband. However, in Malaysia Utilitarian Outcome did not have influence on behavioral intention to adopt broadband [23]. While South Korea has had the highest penetration of broadband in world [25], its broadband adoption was pushed by online gaming hence, motivated entirely by hedonic outcome (HO). After a thorough analysis of broadband adoption in both developed and developing country, household adoption and non adoption can be understood in an in-depth level and best practice can be learned from various countries to increase broadband adoption in Thailand.

\section{CONCEPTUAL Framework}

As shown in Fig. 2, the conceptual framework in this 
research study is taken from[26]. The conceptual framework represents household behavior intention to adopt broadband as a dependent variable which is affect by a number of independent variables which are Utilitarian Outcome (UO), Hedonic Outcome (HO), Social Influence (SI), Self Efficacy (SE), and Facilitating Resources Conditions (FCR). In conducting this research, it helps conclude factors significantly related to behavioral intention to adopt broadband in Thailand, which will contribute to policies required to foster broadband adoption.

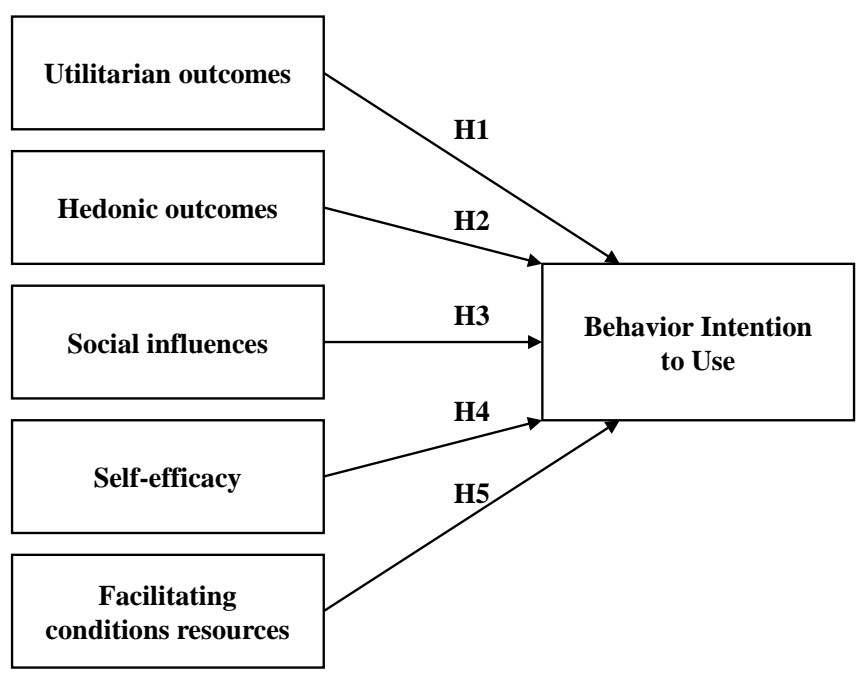

Fig. 2. Conceptual model.

\section{Methodology}

To examine the influential factors on broadband adoption in Mae FahLuang University, quantitative research is adopted in the form of survey research. To evaluate, qualitative research is used to collect, analyze and interpret intangible information and is used to study a smaller sample than in quantitative analysis. As an unstructured approach, qualitative research is used to study in-depth the process or content of a theory that one cannot extract from quantitative research. Contrarily, quantitative research is usually preferred by researchers who want to study a large sample and generalize the results on the whole population. It is a rather structure and conclusive and more appropriate to establish cause and effect among variables.

Therefore to study the influence of factors on broadband adoption in Mae FahLuang University and generalize it to the same age group and same culture, a quantitative research is deemed most appropriate. Data collection is done via means of questionnaire survey where items for the construct in the questionnaire is generated via means of reviewing the literature.

\section{A. Population and Sampling}

The total population of students in Mae FahLuang University is equal to 9,736 individuals. The Taro Yamane technique was applied to calculate the number of samples required from the population of 9736 individuals. Therefore, choosing the $95 \%$ confidence level and allowing only $5 \%$ sampling error, as indicated in Table I for 10,000 population size, the sample size is 385 .
TABLE I: SAMPLE SIZE FOR $\pm 3 \%, \pm 5 \%, \pm 7 \%$ AND $\pm 10 \%$ PRECISION LEVELS WHERE CONFIDENCE LEVEL IS $95 \%$ AND $P=.5$.

\begin{tabular}{|c|c|c|c|c|}
\hline \multirow{2}{*}{$\begin{array}{c}\text { Size of } \\
\text { Population }\end{array}$} & \multicolumn{4}{|c|}{ Sample Size (n) for Precision (e) of: } \\
\hline & $\pm 3 \%$ & $\pm 5 \%$ & $\pm 7 \%$ & $\pm 10 \%$ \\
\hline 500 & $a$ & 222 & 145 & 83 \\
\hline 600 & $a$ & 240 & 152 & 86 \\
\hline 700 & $a$ & 255 & 158 & 88 \\
\hline 800 & $a$ & 267 & 163 & 89 \\
\hline 900 & $a$ & 277 & 166 & 90 \\
\hline 1,000 & $a$ & 286 & 169 & 91 \\
\hline 2,000 & 714 & 333 & 185 & 95 \\
\hline 3,000 & 811 & 353 & 191 & 97 \\
\hline 4,000 & 870 & 364 & 194 & 98 \\
\hline 5,000 & 909 & 370 & 196 & 98 \\
\hline 6,000 & 938 & 375 & 197 & 98 \\
\hline 7,000 & 959 & 378 & 198 & 99 \\
\hline 8,000 & 976 & 381 & 199 & 99 \\
\hline 9,000 & 989 & 383 & 200 & 99 \\
\hline 10,000 & 1,000 & 385 & 200 & 99 \\
\hline 15,000 & 1,034 & 390 & 201 & 99 \\
\hline 20,000 & 1,053 & 392 & 204 & 100 \\
\hline 25,000 & 1,064 & 394 & 204 & 100 \\
\hline 50,000 & 1,087 & 397 & 204 & 100 \\
\hline 100,000 & 1,099 & 398 & 204 & 100 \\
\hline$>100,000$ & 1,111 & 400 & 204 & 100 \\
\hline
\end{tabular}

$a=$ Assumption of normal population is poor (Yamane, 1967). The entire population should be sampled.

\section{B. Variables}

In determining the factors that influenced broadband adoption, five variables were selected from the literature which includes Utilitarian Outcome (UO), Hedonic Outcomes (HO), Social Influence (SI), Self Efficacy (SE)and Facilitating Conditions Resources (FCR).

\section{Data Collection Procedure}

First the population of students in Mae FahLuang University was identified for sampling via the university website. Secondly, a formal request was sent to the Dean and a follow up call was made to request for that the questionnaire be posted online on the website for two months for data collection.

\section{Measurement Instrument}

The questionnaire has two parts; first part measures the demographic characteristics of the respondents, including the gender, age, income etc. The second part of the questionnaire has likert scale items for the five constructs derived from the secondary sources in the literature review.

\section{E. Evaluation of the Questionnaire}

A pilot study or pre-test was conducted to test the validity and reliability of the questionnaire with a sample size of 30 . The Cronbach's Alpha of the pilot study in Table II.

The pilot study for sample size of 30 concluded that Cronbach Alpha of all constructs are above 0.7 and all constructs average to over 0.9 indicating a very good and reliable measure. 
TABLE II: CRONBACH ALPHA

\begin{tabular}{cc}
\hline \hline Construct & Cronbach' Alpha \\
\hline Utilitarian outcomes & 0.848 \\
Hedonic outcomes & 0.892 \\
Social influences & 0.863 \\
Self-efficacy & 0.909 \\
Facilitating conditions resources & 0.898 \\
Behavior Intention & 0.901 \\
Average & 0.969 \\
Utilitarian outcomes & 0.848 \\
Hedonic outcomes & 0.892 \\
\hline \hline
\end{tabular}

\section{F. Hypothesis Testing}

H1. Utilitarian Outcomes has a positive influence on Adoption of Broadband in Households of Mae FahLuang University Students

H2 Hedonic Outcomes has a positive influence on Adoption of Broadband in Households of Mae FahLuang University Students

H3. Social Influences has a positive influence on Adoption of Broadband in Households of Mae FahLuang University Students

H4. Self Efficacy has a positive influence on Adoption of Broadband in Households of Mae FahLuang University Students

H5. Facilitating Conditions Resources has a positive influence on Adoption of Broadband in Households of Mae FahLuang University Students

Overall Behavior Intention has a has a positive influence on Adoption of Broadband in Households of Mae FahLuang University Students

\section{G. Results}

As shown in Table III, the correlation analysis all factors has a significant and positive relation with behavioral intention to adopt broadband.

TABLE III: CORRELATIONS

\begin{tabular}{|c|c|c|c|c|c|c|c|}
\hline & & uo & ho & si & $\mathrm{Se}$ & fcr & bi \\
\hline \multirow[t]{3}{*}{ uo } & Pearson Correlation & 1 & $.234^{*}$ & $.389 *$ & $.467 *$ & $.247 *$ & $.309 *$ \\
\hline & Sig. (2-tailed) & & .000 & .000 & .000 & .000 & .000 \\
\hline & $\mathrm{N}$ & 526 & 526 & 526 & 526 & 526 & 526 \\
\hline \multirow[t]{3}{*}{ ho } & Pearson Correlation & $.234^{*}$ & 1 & $.368 *$ & $.391 *$ & $.299 *$ & $.349 *$ \\
\hline & Sig. (2-tailed) & .000 & & .000 & .000 & .000 & .000 \\
\hline & $\mathrm{N}$ & 526 & 526 & 526 & 526 & 526 & 526 \\
\hline \multirow[t]{3}{*}{ si } & Pearson Correlation & $.389 *$ & $.368^{*}$ & 1 & $.520 *$ & $.355^{*}$ & $.490 *$ \\
\hline & Sig. (2-tailed) & .000 & .000 & & .000 & .000 & .000 \\
\hline & $\mathrm{N}$ & 526 & 526 & 526 & 526 & 526 & 526 \\
\hline \multirow[t]{3}{*}{$\mathrm{Se}$} & Pearson Correlation & $.467 *$ & $.391 *$ & $.520 *$ & 1 & $.484 *$ & $.513 *$ \\
\hline & Sig. (2-tailed) & .000 & .000 & .000 & & .000 & .000 \\
\hline & $\mathrm{N}$ & 526 & 526 & 526 & 526 & 526 & 526 \\
\hline \multirow[t]{3}{*}{ Fcr } & Pearson Correlation & $.247 *$ & $.299 *$ & $.355^{*}$ & $.484 *$ & 1 & $.429 *$ \\
\hline & Sig. (2-tailed) & .000 & .000 & .000 & .000 & & .000 \\
\hline & $\mathrm{N}$ & 526 & 526 & 526 & 526 & 526 & 526 \\
\hline \multirow[t]{3}{*}{$\mathrm{Bi}$} & Pearson Correlation & $.309 *$ & $.349 *$ & $.490 *$ & $.513 *$ & $.429 *$ & 1 \\
\hline & Sig. (2-tailed) & .000 & .000 & .000 & .000 & .000 & \\
\hline & $\mathrm{N}$ & 526 & 526 & 526 & 526 & 526 & 526 \\
\hline
\end{tabular}

* Correlation is significant at the 0.01 level (2-tailed)
Shown in Table IV, Factors such Hedonic Outcome, Self Efficacy, Social Influence, Utilitarian Outcome and Facilitating Resources Conditions can explain the Behavioral Intention to adopt Broadband by $36.4 \%$ as shown in Adjusted R Square in Table IV.

\begin{tabular}{cccc}
\multicolumn{4}{c}{ TABLE IV: RESULTS } \\
\hline \hline Model & R & R Square & Adjusted R Square \\
\hline 1 & $.309^{\mathrm{a}}$ & .096 & .094 \\
2 & $.420^{\mathrm{b}}$ & .177 & .174 \\
3 & $.534^{\mathrm{c}}$ & .286 & .281 \\
4 & $.587^{\mathrm{d}}$ & .344 & .339 \\
5 & $.608^{\mathrm{e}}$ & .370 & .364 \\
\hline \hline
\end{tabular}

TABLE V: ANOVA

\begin{tabular}{|c|c|c|c|c|c|c|}
\hline & Model & $\begin{array}{l}\text { Sum of } \\
\text { Squares }\end{array}$ & Df & $\begin{array}{c}\text { Mean } \\
\text { Square }\end{array}$ & $\mathrm{F}$ & Sig. \\
\hline \multirow[t]{3}{*}{1} & Regression & 29.836 & 1 & 29.836 & 55.382 & $.000 \mathrm{a}$ \\
\hline & Residual & 282.296 & 524 & .539 & & \\
\hline & Total & 312.132 & 525 & & & \\
\hline \multirow[t]{3}{*}{2} & Regression & 55.181 & 2 & 27.591 & 56.158 & $.000 \mathrm{~b}$ \\
\hline & Residual & 256.951 & 523 & .491 & & \\
\hline & Total & 312.132 & 525 & & & \\
\hline \multirow[t]{3}{*}{3} & Regression & 89.142 & 3 & 29.714 & 69.558 & $.000 \mathrm{c}$ \\
\hline & Residual & 222.990 & 522 & .427 & & \\
\hline & Total & 312.132 & 525 & & & \\
\hline \multirow[t]{3}{*}{4} & Regression & 107.491 & 4 & 26.873 & 68.416 & $.000 \mathrm{~d}$ \\
\hline & Residual & 204.641 & 521 & .393 & & \\
\hline & Total & 312.132 & 525 & & & \\
\hline \multirow[t]{3}{*}{5} & Regression & 115.548 & 5 & 23.110 & 61.129 & $.000 \mathrm{e}$ \\
\hline & Residual & 196.584 & 520 & .378 & & \\
\hline & Total & 312.132 & 525 & & & \\
\hline
\end{tabular}

From the Table V, F-statistics test is adopted to test whether at least one independent variable has a significant relationship with the dependent variable. At $95 \%$ confidence level, significant level is 0.000 indicating that at least one independent variable has a relationship with dependent variable Behavioral Intention to adopt Broadband (BI).

\begin{tabular}{|c|c|c|c|c|c|c|}
\hline \multicolumn{7}{|c|}{ TABLE VI: COEFFICIENTS } \\
\hline & \multirow[t]{2}{*}{ Model } & \multicolumn{2}{|c|}{$\begin{array}{l}\text { Un-standardized } \\
\text { Coefficients }\end{array}$} & \multirow{2}{*}{$\begin{array}{c}\begin{array}{c}\text { Standardized } \\
\text { Coefficient }\end{array} \\
\text { Beta }\end{array}$} & \multirow[t]{2}{*}{$\mathrm{t}$} & \multirow[t]{2}{*}{ Sig. } \\
\hline & & B & Std Error & & & \\
\hline \multirow{6}{*}{1} & (Constant) & .274 & .215 & & 1.278 & .202 \\
\hline & UO & .035 & .047 & .030 & .758 & .449 \\
\hline & $\mathrm{HO}$ & .114 & .044 & .101 & 2.593 & .010 \\
\hline & SI & .249 & .042 & .251 & 5.882 & .000 \\
\hline & SE & .272 & .054 & .239 & 5.073 & .000 \\
\hline & FCR & .266 & .058 & .186 & 4.617 & .000 \\
\hline
\end{tabular}

As shown in Table VI, the multiple regression analysis was also conducted to examine the relationship between Utilitarian Outcome (UO), Hedonic Outcome (HO), Social Influence (SI), Self Efficacy (SE) and Facilitating Resources Conditions (FCR). The hypothesis testing for this research are: 
H1: Utilitarian Outcomes has a positive influence on Adoption of Broadband in Households of Mae FahLuang University Students

The regression analysis in Table IV indicated that the significant level for Utilitarian Outcome is 0.449 hence, null hypothesis 1: "Utilitarian Outcome has no influence on Adoption of Broadband in Households of Mae FahLuang University Students" is accepted as 0.449 significance is 0.05 at $95 \%$ confidence interval. As a result, it is concluded that UO has no influence on behavioral intention to adopt broadband (BI).

H2: Hedonic Outcomes has a positive influence on Adoption of Broadband in Households of Mae FahLuang University Students

The regression analysis in Table IV indicated that the significant level for Hedonic outcome is 0.010 which is lesser than 0.005 at $95 \%$ confidence level indicating $\mathrm{H} 2$ is accepted and Null Hypothesis 2 is rejected. It can be concluded that Hedonic Outcome has a significant positive influence on behavioral intention to adopt broadband (BI).

H3: Social Influences has a positive influence on Adoption of Broadband in Households of Mae FahLuang University Students

The regression analysis in Table IV indicated that the significant level for Social Influence is 0.000 which is lesser than 0.005 at $95 \%$ confidence level indicating $\mathrm{H} 3$ is accepted and Null Hypothesis 3 is rejected. It can be concluded that Social Influence has a significant positive influence on behavioral intention to adopt broadband (BI).

H4: Self Efficacy has a positive influence on Adoption of Broadband in Households of Mae FahLuang University Students

The regression analysis in Table IV indicated that the significant level for Self Efficacy is 0.000 which is lesser than 0.005 at $95 \%$ confidence level indicating $\mathrm{H} 4$ is accepted and Null Hypothesis 4 is rejected. It can be concluded that Self Efficacy has a significant positive influence on behavioral intention to adopt broadband (BI).

H5: Facilitating Conditions Resources has a positive influence on Adoption of Broadband in Households of Mae FahLuang University Students

The regression analysis in Table IV indicated that the significant level for Facilitating Resources Conditions is 0.000 which is lesser than 0.005 at $95 \%$ confidence level indicating $\mathrm{H} 5$ is accepted and Null Hypothesis 5 is rejected. It can be concluded that Facilitating Resources Conditions has a significant positive influence on behavioral intention to adopt broadband (BI).

Overall Behavior Intention has a has a positive influence on Adoption of Broadband in Households of Mae FahLuang University Students

Overall, all the regression analysis indicated that HO, SI, SE and FCR as independent variables have a significant influence on BI with $0.000 \mathrm{sig}$ at $95 \%$ confidence interval. Therefore, it can be concluded that

$$
Y 1=274+114(\mathrm{HO})+249(\mathrm{SI})+272(\mathrm{SE})+266(\mathrm{FCR})
$$

Therefore as the model is shown in Fig. 3, the predictor model consists four of the independent variables out of five predictor variables. The behavioral intention to adopt broadband highest weight comes from higher levels of self-efficacy, then facilitating conditions resources and social influence. While, hedonic outcomes has the lowest weight in behavioral intention to adopt broadband.

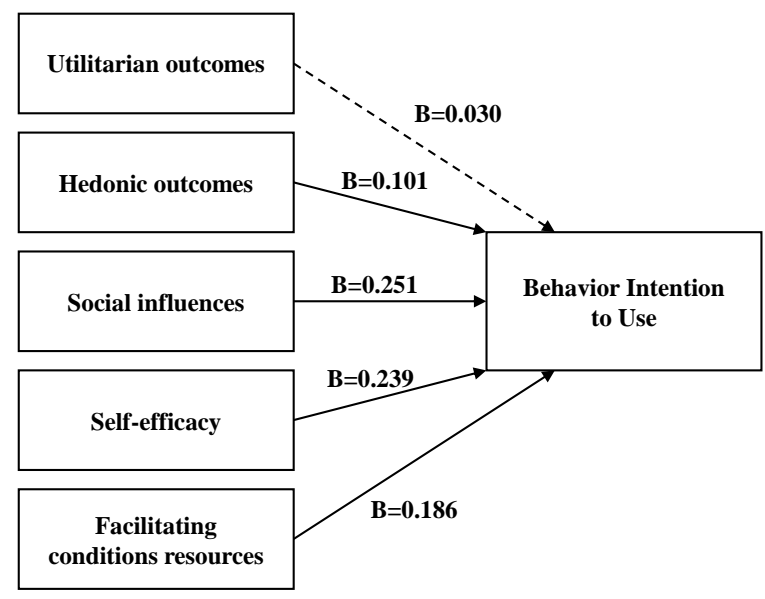

Fig. 3. Influence of factors motivating broadband adoption.

\section{DISCUSSION}

The aim of this study is to study the factors that influence behavioral intention to adopt broadband in Thailand. Similar to the case of Thailand, developing countries such as Pakistan, Bangladesh and Malaysia are facing slower rates to broadband adoption than other countries such as UK, South Korea and Japan due to slow IT infrastructure development. The result indicated in this study reveals that Facilitating Resources Conditions (FCR), Self Efficacy (SE), Social Influence (SI) and Hedonic Outcome (HO) are amongst the factors that influence behavioral intention to adopt Broadband in Thailand. While the results in UK as a developed country reveal that all of the same factors that influence behavioral intention to adopt Broadband in Thailand with the exception Utilitarian Outcome (UO) which influences broadband adoption UK. Similarly in Bangladesh, factors that influence Broadband adoption are Utilitarian Outcome, Hedonic Outcome, Social Influence and Facilitating Resources Conditions. While Utilitarian Outcome influences Broadband Adoption in United Kingdom and Bangladesh, it does not influence broadband adoption in Pakistan, Malaysia or in Thailand. The results reveal that culture has a lot to do with broadband adoption where United Kingdom and Bangladesh has very advanced educational system and higher mindset for education than other countries. On the other hand, Pakistan broadband adoption is not influenced by hedonic outcome, unlike United Kingdom, Bangladesh, Malaysia and Thailand. Nevertheless, in Thailand hedonic outcome has the least weight in behavioral intention to adopt broadband. The results in broadband adoption in Thailand are exactly same as Malaysia where Hedonic Outcome, Self Efficacy, Facilitating Conditions Resources and Social Influence motivate broadband adoption. Therefore, it can be expected that policies for broadband adoption in Thailand can be very similar to that of Malaysia. While broadband adoption in South Korea is motivated by online gaming which was used 
to motivate highest broadband penetration, similar tactics cannot be adopted by Thailand due to different results revealed in this study.

As for the broadband policies in Thailand, first factor is facilitating conditions resources (FCR) which has the highest weight in influencing broadband adoption. Therefore, ability to afford broadband and computer for broadband has the highest influence for broadband adoption in this study. Therefore, a policy by ICT ministry and NBTC has to ensure prices of broadband are compatible with average income of users so general public are motivated to subscribe to broadband. On the other hand, self efficacy of perceived skill of users in operating computers and internet also have high influence on broadband in this study, ICT and NBTC should also have policies and projects to educate general public and increase their computer and internet use skills. As for users who do not have adequate income to subscribe to broadband, ICT and NBTC institutions should also promote Internet Service Providers (ISP) to provide internet at lower costs. ICT and NBTC should also have community centers for free internet and free training programs to increase their self efficacy. Thirdly, social influence also motivates broadband adoption. Rather than using newspapers and media to increase broadband adoption, perhaps it is better to educate general public on benefits of broadband. As a result, their word of mouth can help increase motivation to adopt broadband in a community. Lastly, hedonic outcome has the least influence on broadband adoption among all four factors; therefore, entertainment is not an important factor in increasing adoption to broadband. Nevertheless, it has a significant influence on broadband adoption in comparison with Utilitarian outcome. Therefore, in promoting and increasing broadband adoption in Thailand, policies may focus on informing users about entertainment purposes rather than household purposes. Therefore, entertainment purposes (hedonic outcome) interests Thai users more than educational or household benefit (utilitarian outcome).

\section{CONCLUSION}

The aim of this study is to study the factors that influence behavioral intention to adopt broadband in Thailand. This study has provided an analysis of Thailand in comparison to other developed and developing countries that study broadband adoption. The study revealed that amongst all five factors, Facilitating Conditions Resources, Self Efficacy and Social Influence have highest influence on Broadband Adoption. While Hedonic Outcome has a significant impact on influence to adopt broadband in Thailand over Utilitarian Outcome, which has no impact on behavioral intention to adopt broadband. The results in this study have revealed a direction for ICT and NBTC on how to promote adoption of broadband in Thailand.

\section{REFERENCES}

[1] R. Katz, "The impact of broadband on the economy: Research to date and policy issues," Trends in Telecommunication Reform 2010, vol. 11 , pp. 23-82, 2011
[2] Y. Dwivedi and Z. Irani, "Understanding the adopters and non-adopters of broadband," Communications of the ACM, vol. 52, pp. 122-125, 2009.

[3] S. Lee and J. S. Brown, "Examining broadband adoption factors: an empirical analysis between countries," Info, vol. 10, pp. 25-39, 2008.

[4] L. Hitt and P. Tambe, "Broadband adoption and content consumption," Information Economics and Policy, vol. 19, pp. 362-378, 2007.

[5] Y. K. Dwivedi, B. Lal, and M. D. Williams, "Managing consumer adoption of broadband: examining drivers and barriers," Industrial Management and Data Systems, vol. 109, pp. 357-369, 2009.

[6] S. Oh, J. Ahn, and B. Kim, "Adoption of broadband Internet in Korea: the role of experience in building attitudes," Journal of Information Technology, vol. 18, pp. 267-280, 2003.

[7] Y. Dwivedi, K. Khoumbati, M. Williams, and B. Lal, "Factors affecting consumers' behavioural intention to adopt broadband in Pakistan," Transforming Government: People, Process and Policy, vol. 1, pp. 285-297, 2007.

[8] Y. K. Dwivedi, J. Choudrie, and W.-P. Brinkman, "Development of a survey instrument to examine consumer adoption of broadband," Industrial Management and Data Systems, vol. 106, pp. 700-718, 2006.

[9] I. Ajzen and M. Fishbein, Understanding Attitudes and Predicting Social Behaviour, 1980.

[10] F. D. Davis, R. P. Bagozzi, and P. R. Warshaw, "User acceptance of computer technology: a comparison of two theoretical models," Management Science, vol. 35, pp. 982-1003, 1989.

[11] I. Ajzen, "The theory of planned behavior," Organizational Behavior and Human Decision Processes, vol. 50, pp. 179-211, 1991.

[12] K. Mathieson, "Predicting user intentions: comparing the technology acceptance model with the theory of planned behavior," Information Systems Research, vol. 2, pp. 173-191, 1991.

[13] R. L. Thompson, C. A. Higgins, and J. M. Howell, "Personal computing: toward a conceptual model of utilization," MIS Quarterly, pp. 125-143, 1991

[14] S. Taylor and P. Todd, "Decomposition and crossover effects in the theory of planned behavior: A study of consumer adoption intentions," International Journal of Research in Marketing, vol. 12, pp. 137-155, 1995.

[15] J. C. Brancheau and J. C. Wetherbe, "The adoption of spreadsheet software: testing innovation diffusion theory in the context of end-user computing," Information Systems Research, vol. 1, pp. 115-143, 1990.

[16] R. Agarwal and J. Prasad, "The role of innovation characteristics and perceived voluntariness in the acceptance of information technologies," Decision Sciences, vol. 28, pp. 557-582, 1997.

[17] E. M. Rogers, "Diffusion of preventive innovations," Addictive Behaviors, vol. 27, pp. 989-993, 2002.

[18] V. Venkatesh and F. D. Davis, "A theoretical extension of the technology acceptance model: four longitudinal field studies," Management Science, vol. 46, pp. 186-204, 2000.

[19] V. Venkatesh, M. G. Morris, G. B. Davis, and F. D. Davis, "User acceptance of information technology: Toward a unified view," MIS Quarterly, pp. 425-478, 2003.

[20] J. Choudrie and Y. K. Dwivedi, "Investigating the research approaches for examining technology adoption issues," Journal of Research Practice, vol. 1, p. Article D1, 2005.

[21] Y. K. Dwivedi, N. Khan, and A. Papazafeiropoulou, "Consumer adoption and usage of broadband in Bangladesh," Electronic Government, an International Journal, vol. 4, pp. 299-313, 2007.

[22] Y. Dwivedi, B. Lal, Z. Irani, and M. Williams. (2007). A Logistic Regression Analysis to Examine Factors Affecting Broadband Adoption in UK. [Online]. Available: http://is2.1se.ac.uk/asp/aspecis/20070044.pdf

[23] M. H. Selamat, Y. K. Dwivedi, A. Wahab, M. Syahir, M. Samsudin, M Amir et al., "Factors affecting Malaysian accountants' broadband adoption and use behavior," 2008.

[24] Y. K. Dwivedi and V. Weerakkody, "Examining the factors affecting the adoption of broadband in the Kingdom of Saudi Arabia," Electronic Government, An International Journal, vol. 4, pp. 43-58, 2007.

[25] K. Yun, H. Lee, and S.-H. Lim, "The growth of broadband Internet connections in South Korea: contributing factors," Asia-Pacific Research Center, Stanford Institute for International Studies, 2002.

[26] Y. K. Dwivedi, B. Lal, and M. D. Williams, "Managing consumer adoption of broadband: examining drivers and barriers," Industrial Management and Data Systems, vol. 109, pp. 357-369, 2008. 


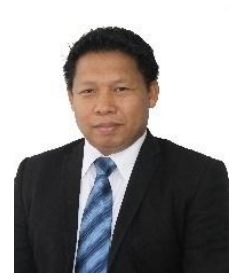

Noppadol Tiamnara was born on November 12 1968 in Pah Na Korn Sri Ayuttaya, Thailand. He received the degree diploma of vocational education in industrial technology from South-East Asia Colledge, Thailand, 1990, and the bachelor degree of electrical engineering from Saint John's University, Thailand, 2002. He received the master degree of master of science (technology management) from Thammasart University, Thailand, 2012. Since 2006, he has been working in national broadcasting and telecommunications commission as assistant of vice chairman of national broadcasting and telecommunication commission (NBTC). His research interests include LTE design, wireless systems, microstrip antenna and applied electromagnetic.

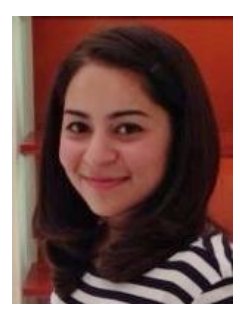

Navneet K. Madan was born in Bangkok, Thailand on April 22, 1987. She received her bachelor of business administration in international business management from Mahidol University in 2008, and received master of science degree in strategic management and marketing, Middlesex University, London, United Kingdom. She has been working as an assistant to vice chairman in National Broadcasting and Telecommunications, Bangkok, Thailand since January 2012. Her research interests are in spectrum management strategic flexibility, market orientation and environmental uncertainty in fast clockspeed industries.

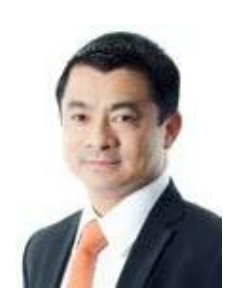

Settapong Malisuwan was born on March 24, 1966 in Bangkok, Thailand. He received his Ph.D. in electrical engineering (telecommunications), specializing in EMI/EMC from Florida Atlantic University (State University System of Florida), Boca Raton in 2000. He received an MSc in electrical engineering in mobile communications system, from George Washington University in 1996, an MSc in electrical engineering from Georgia Institute of Technology in 1992 and a BSc in electrical engineering from the Chulachomklao Royal Military Academy, Nakhon-Nayok, Thailand in 1990. He served in the Royal Thai Armed Forces for more than 25 years. His research interests are in efficient spectrum management and Telecommunications policy and management. Col. Dr. Settapong Malisuwan is currently the elected vice chairman and board member in the National Broadcasting and Telecommunications Commission, Thailand. 